\title{
Response of vegetation to the 2003 European drought was mitigated by height
}

\author{
S. L. Bevan, S. O. Los, and P. R. J. North \\ Geography Department, College of Science, Swansea University, Singleton Park, Swansea, SA2 8PP, UK \\ Correspondence to: S. L. Bevan (s.1.bevan@swansea.ac.uk)
}

Received: 23 September 2013 - Published in Biogeosciences Discuss.: 18 October 2013

Revised: 3 April 2014 - Accepted: 28 April 2014 - Published: 4 June 2014

\begin{abstract}
The effects on climate of land-cover change, predominantly from the conversion of forests to crops or grassland, are reasonably well understood for low and high latitudes but are largely unknown for temperate latitudes. The main reason for this gap in our knowledge is that there are compensating effects on the energy and water balance that are related to changes in land-surface albedo, soil evaporation and plant transpiration. We analyse how vegetation height affected the response of vegetation during the 2003 European drought using precipitation data, temperature data, normalized difference vegetation index data and a new vegetation height data set obtained from the Geoscience Laser Altimeter System (GLAS) on the Ice, Cloud and land Elevation Satellite (ICESat). At the height of the 2003 drought we find for tall vegetation a significantly smaller decrease in vegetation index and a smaller diurnal temperature (DTR) range, indicating less water stress and drought impacts on tall vegetation. Over Germany for example, $98 \%$ of significant correlations showed a smaller anomaly in vegetation index anomaly with greater height, and $95 \%$ of significant correlations showed a smaller DTR with greater vegetation height. Over France the equivalent percentages were 94 and $88 \%$, respectively. Vegetation height is likely associated with greater rooting depth, canopy heat capacity or both. Our results suggest that land-surface models can be improved by better estimates of vegetation height and associated with this a more realistic response to drought.
\end{abstract}

\section{Introduction}

In the present study we aim to obtain a better understanding of the drought response of vegetation in western Europe and thereby address gaps in our understanding of the effects of land-cover change from tall to short cover types in temperate climates. To do so, we analyse climate and vegetation data, including a new vegetation height data set, collected during the West European 2003 extreme drought.

Summer (June, July, August) 2003 temperatures over Europe were probably the warmest since 1500 (Luterbacher et al., 2004; García-Herrera et al., 2010), with periods of exceptional heat occurring in June and early August (Schär et al., 2004; García-Herrera et al., 2010). Over large areas JJA temperatures exceeded the $1961-1990$ average by $3{ }^{\circ} \mathrm{C}$, a value equivalent to 5 standard deviations above the $30 \mathrm{yr}$ JJA average (Schär et al., 2004). It is estimated that the heatwave contributed to the global atmospheric $\mathrm{CO}_{2}$ growth rate (Ciais et al., 2005), led to a reduction in crop growth and caused an estimated 40000 extra deaths (García-Herrera et al., 2010). A key component in the amplification and persistence of the heatwave was a spring precipitation deficit (Loew et al., 2009) followed by low spring soil water content resulting in reduced evapotranspiration, reduced latent cooling, and increased sensible heat fluxes (Fischer et al., 2007).

The extreme conditions of summer 2003 had a significant impact on biomass productivity over much of Europe with dependencies on geographic location, topographic elevation, and vegetation type as revealed in a variety of modelling and observational studies (Gobron et al., 2005; Coret et al., 2005; Jolly et al., 2005; Lobo and Maisongrande, 2006). Vegetation was affected as early as March in northern France, Belgium, the Netherlands, Luxembourg and Germany, and the impact spread east and south through the summer (Gobron et al., 2005). In southwestern France different vegetation types were shown to respond differently to the drought, with forests being less affected than either meadows, spring 
wheat or maize (Coret et al., 2005). Zaitchik et al. (2006) also found that in France the vegetation response to the drought and heatwave was clearly a function of land-cover type, with the impact showing earlier, and becoming more severe, for crops and pastures than for forests. The difference was greatest at the height of the heatwave in mid-August. Water stress, as measured by the difference between precipitation and potential evapotranspiration, was shown to be a major factor in the geographic distribution of vegetation response to the north and south of the Pyrenees (Lobo and Maisongrande, 2006). However, at high altitudes, in the Swiss Alps for example, the reduced snow cover meant that photosynthetic activity actually increased (Jolly et al., 2005).

The importance for climate in understanding the vegetation response to drought lies in the potential feedbacks between vegetation and the atmosphere. Changes in evapotranspiration, albedo and aerodynamic roughness associated with changes in vegetation (e.g. canopy cover and shape, stomatal closure, change in leaf angle, number of leaves, and variations in vegetation height) affect the transfer of energy and water between the land surface and atmosphere. Various studies find that vegetation plays a role in recycling water from the land to the atmosphere through evapotranspiration which is then returned in the form of precipitation (Dirmeyer, 1994; van den Hurk et al., 2003). Fischer et al. (2007) established that soil-moisture depletion propagated the severity of the 2003 drought. Vegetation, in regulating the transfer of soil moisture to the atmosphere is therefore potentially an important factor in mitigating or enhancing the effects of a drought.

Land cover in western Europe has changed significantly over the past two millennia; original vegetation cover, for a substantial part consisting of trees, has to a large extent been replaced by short vegetation, predominantly pasture and crops. Land-cover change continued during the 20th century as agriculture became more mechanized and efficient and small parcels of land were merged into large parcels. During the past decades the declining trends in forest cover have reversed with a proportion of agricultural land being taken out of production and converted to natural land (Klein Goldewijk and Ramankutty, 2004). For some time there has been intense speculation on the effect of land-cover change on climate, e.g. Sagan et al. (1979) suggest that the conversion of land was accompanied by changes in albedo and that these likely affected the regional climate. Conversion of land may have an impact on the atmosphere and several regions have been identified where feedbacks between vegetation and precipitation are likely to occur. One such region is the Sahel, the region south of the Sahara, where both models and observations indicate a positive feedback between vegetation greenness and precipitation (Charney et al., 1977; Los et al., 2006; Xue et al., 2010). Another region where similar feedbacks have been identified in model simulations is the Amazon, e.g. Costa and Foley (2000), whereas in high-latitude boreal forests a positive feedback between temperature and tree cover is likely (Betts et al., 2001a, b; Thomas and Rowntree, 1992; Bonan et al., 1992), see Bonan (2008) for an overview.

Much larger uncertainties exist when it comes to assessing the effect of land-cover change in temperate regions. A recent comparison of seven land-surface models highlights the uncertainty in the effects of tall versus short vegetation on the energy and water balance in temperate latitudes. Five models showed a cooling during summer as a result of land-cover change, one model a warming, and one showed no significant response (Pitman et al., 2009). The differing responses of the models were attributed to differences in the description of processes such as shading effects and albedo effects as well as differences in estimates of land-cover change.

Vegetation response to drought is likely to have a height dependence. An analysis of European flux-tower sites (Teuling et al., 2010) showed that, at the beginning of the 2003 heatwave, grassland and herbaceous vegetation dampened local increases in temperature associated with increased radiation and reduced precipitation via enhanced (evapo)transpiration. As soil water was depleted by the evaporative demand, temperatures started to increase. Tall vegetation on the other hand showed an initial larger increase in temperature but this was subsequently dampened because the closed canopy shelters the soil from solar radiation and this reduces soil evaporation and forms a barrier for water vapour flux from the canopy layer to the atmosphere (Teuling et al., 2010). In addition, tall vegetation probably has access to deeper soil water. Across all biomes on a global basis the average maximum depths at which trees, shrubs, and herbaceous plants are able to grow roots are $7.0 \pm 1.2 \mathrm{~m}$, $5.1 \pm 0.8 \mathrm{~m}$, and $2.6 \pm 0.1 \mathrm{~m}$, respectively (Canadell et al., 1996). Schenk and Jackson (2002a) also found a strong positive relationship between above-ground biomass size and both rooting depth and lateral spread of root systems.

The aim of the present research is to explore the response of vegetation to drought in Western Europe in further detail. In particular we wish to (1) investigate whether vegetation height is associated with greater drought tolerance of vegetation across Europe; this was suggested to be of importance by a local analysis of flux-tower sites (Teuling et al., 2010), and (2) explore mechanisms to explain variations in drought tolerance of vegetation, with a focus on associations between vegetation height, greater rooting depth and increased canopy heat capacity. We use a new data set of vegetation heights from the ICESat GLAS instrument to obtain continuous measures of vegetation height and reveal the differing responses of short and tall vegetation to the 2003 drought across Europe. We use a range of data sets in addition to the vegetation heights: MODIS Normalized Difference Vegetation Index (NDVI) data - a measure linked to the amount of solar radiation absorbed for photosynthesis and net primary productivity of vegetation, difference in MODIS day and night surface temperature data that are linked to variations in canopy heat capacity, precipitation data, reanalysis temperature data and land-cover type from 
the CORINE database. We analyse how the response of vegetation to the 2003 drought as manifested in the NDVI and the diurnal temperature range (DTR) is affected by land-cover type and vegetation height. We also use databases of rooting depth (Schenk and Jackson, 2002b, 2009; Hall et al., 2006) and soil-moisture availability (Kleidon, 2011; Kleidon and Heimann, 1998; Hall et al., 2006) to test the hypothesis that the differing responses are driven by access to soil moisture.

\section{Data}

Nine-tile mosaics of MODIS Terra NDVI (MOD13A2) Collection 5 were downloaded for the period 2000 to 2012. The NDVI is expressed as the difference between reflected solar radiation in the infra-red $\left(\rho_{2}\right)$ and red $\left(\rho_{1}\right)$ wavelengths normalized by their sum: NDVI $=\left(\rho_{2}-\rho_{1}\right) /\left(\rho_{2}+\rho_{1}\right)$. Temporal changes in NDVI are proportional to temporal changes in fAPAR (Sellers, 1985; Myneni and Williams, 1994), and vegetation net primary productivity. The NDVI fields are at a spatial resolution of $1000 \mathrm{~m}$ and cover the area shown in Fig. 1 . The data were screened using the quality flags to remove pixels having an overall usefulness of 11 - this excludes pixels with high aerosols, clouds or adjacent clouds, and possible cloud shadows (Samanta et al., 2010). The MODIS NDVI 16-day composites were linearly interpolated in time to fill gaps in the data that resulted from the quality screening. Anomalies for all 16-day periods were computed relative to their 2000 to 2010 average.

ECMWF ERA-Interim monthly means of daily $2 \mathrm{~m}$ air temperature at a spatial resolution of $1.5^{\circ}$ were obtained from the ECMWF Data Server. The data were projected to the MODIS Sinusoidal projection, and were scaled spatially to $1 \mathrm{~km}$ resolution using B-spline smoothing, and scaled in time by averaging to produce fields of mean temperature for the 32-day period prior to each 16-day NDVI composite. Anomalies for the resulting 32-day means were computed relative to the 2000-2010 mean (Berrisford et al., 2011).

Global Precipitation Climatology Project (GPCP) One Degree Daily Precipitation Data Sets (Huffman et al., 2001, 2009,2011 ), were used to generate fields of precipitation anomalies relative to their 2000-2010 mean. The data were projected to the MODIS Sinusoidal projection and were spatially scaled using the same B-spline method as applied to the temperature data. The daily data were accumulated for the same 32-day periods as the temperature data, i.e. each period ends on the starting date of the next NDVI composite.

The DTRs were calculated by subtracting night-time from day-time MODIS Aqua land surface temperatures (LSTs, MYD11A2). These data are 8-day clear-sky averages over the 8 days commencing with the data set date, and have the same coverage and spatial resolution as the NDVI product. The day-time overpass was between 13:40 and 13:50 LT for the region analysed. Data were visually inspected and no further quality control was deemed necessary. Remotely sensed
LSTs are a measurement of radiometric surface temperatures, not air temperatures, and rely on a knowledge of the surface emissivity. Remotely sensed temperatures are often referred to as skin temperatures because they are measured from a very thin surface layer (top leaves, top of bare soil or both). Use of DTRs has the advantage that the impacts of (predominantly spatial) variations in emissivity are smaller in DTRs than in surface temperatures.

Vegetation heights were based on 2003-2009 data from the Geoscience Laser Altimeter System (GLAS) on the Ice, Cloud and land Elevation Satellite (ICESat) (Rosette et al., 2008; Los et al., 2012). Heights are estimated from each GLAS measurement, which has an along-track sampling rate of $172 \mathrm{~m}$ and footprints of approximately $70 \mathrm{~m}$ in diameter, and are filtered to eliminate spurious observations, e.g. data that are affected by clouds, atmosphere and steep terrain (Los et al., 2012). We make use of both point data and gridded data consisting of the 90th percentile of vegetation heights aggregated into $0.5^{\circ} \times 0.5^{\circ}$ bins.

In order to investigate the effect of vegetation class on the response to drought in 2003 we use the Version 16 Corine Land Cover 2000 (CLC2000) $250 \mathrm{~m}$ raster data (EEA, EEA data service). The legend and the grouping into tall and short vegetation types is summarized in Table 1 .

International Satellite Land-Surface Climatology Project (ISLSCP) Initiative II data sets of rooting depth (Schenk and Jackson, 2002b, 2009; Hall et al., 2006) and soil water availability (Kleidon, 2011; Kleidon and Heimann, 1998; Hall et al., 2006) were downloaded from the Oak Ridge National Laboratory Distributed Active Archive Center. The data sets are at a spatial resolution of $1.0^{\circ}$ and based on rooting depths collected from existing literature; over 550 samples from more than 300 locations were included in the database (Schenk and Jackson, 2002b, 2003). Rooting-depth measurements were limited to the first $3 \mathrm{~m}$ of soil. Soil water availability is a modelled product derived for average climatological conditions and is based on the assumptions either that vegetation has adapted to the environment and makes optimum use of water (optimization) (Kleidon and Heimann, 1998; Hall et al., 2006) or that green vegetation indicates that sufficient water is available for transpiration (assimilation) (Knorr, 1997).

\section{Results}

Similar to previous research (e.g. Zaitchik et al., 2006; Reichstein et al., 2007) our analysis starts by investigating the evolution and distribution of the vegetation response to the meteorological conditions of summer 2003. Figure 1 shows the NDVI anomalies, deviations from the multi-year mean significant at the $95 \%$ level, for the 16-day composite periods beginning on 23 April, 26 June and 29 August 2003. April 2003 shows positive NDVI anomalies for central and eastern France, West Germany, the Alps, Northwest Spain 


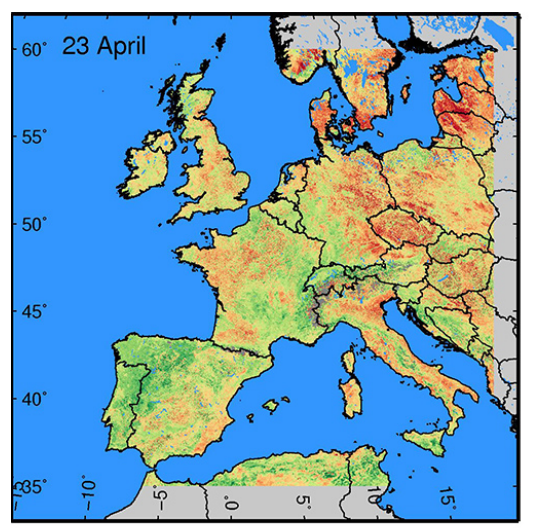

(a)

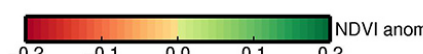

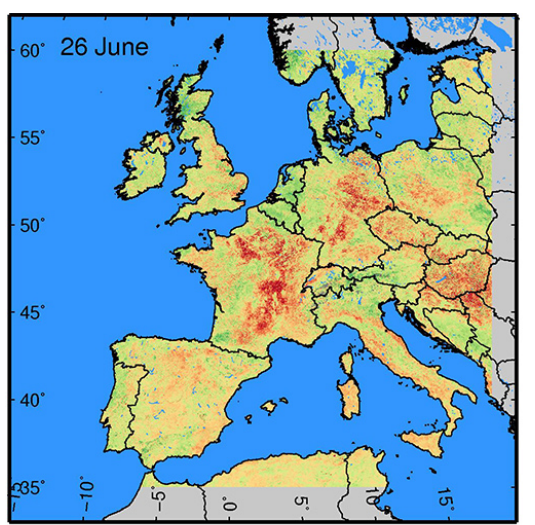

(b)

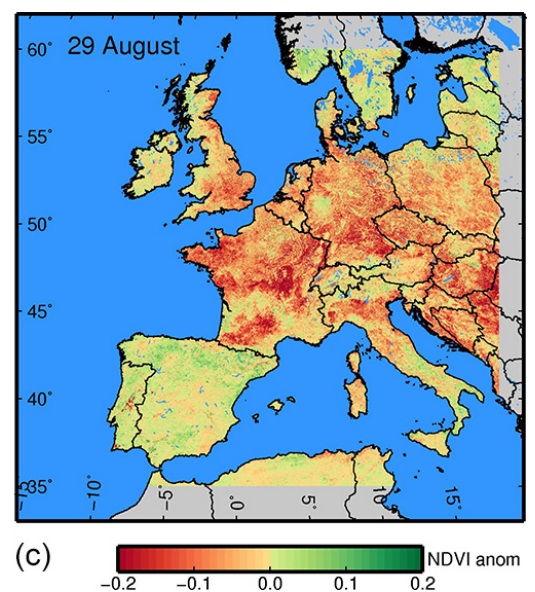

Figure 1. Anomalies in MODIS NDVI for (a) 23 April 2003, (b) 26 June 2003, (c) 29 August 2003. The anomalies are relative to the mean for that date over the period 2000-2010.

Table 1. Corine land-cover classes 2000 (EEA, EEA data service) contributing to the short and tall vegetation groupings discussed in the text.

\begin{tabular}{lll}
\hline Group & Corine Level 2 class & $\begin{array}{l}\text { Corine } \\
\text { CLC_CODE }\end{array}$ \\
\hline \multirow{2}{*}{ Short } & Artificial, non-agricultural & 141,142 \\
& Arable land & $211-213$ \\
& Permanent crops & $221-223$ \\
& Pastures & 231 \\
& Heterogeneous agricultural areas & $241-244$ \\
& Scrub and/or herbaceous & $321-324$ \\
\multirow{2}{*}{ Tall } & vegetation associations & \\
\hline & Forests & $311-313$ \\
\hline
\end{tabular}

and Portugal and northern Scotland associated with the warm early spring (Fig. 1a) (Zaitchik et al., 2006). Large negative NDVI anomalies appear first in central France in mid-June and advance to the north, south and east during the summer eventually including Northwest France, parts of Germany and the eastern UK (Fig. 1b). The most intensive and widespread anomalies are apparent from mid-August (Fig. 1c). By this date, significant negative anomalies are observed over much of central Europe, excluding the Iberian Peninsula and the western parts of the UK. Areas less affected by the drought are southern Italy, Scandinavia and the high-elevation regions of the Alps. The large negative anomalies in central Portugal have been attributed to forest fires (Reichstein et al., 2007).

Research has suggested that overall, reductions in European gross primary productivity (GPP) during the summer of 2003 correlate better with decreased rainfall than with increased temperature (Ciais et al., 2005; Reichstein et al., 2007), although decreased rainfall and increased temperatures are clearly often linked. To investigate the contribu- tion of each parameter we calculate the Pearson's correlation coefficient $(R)$ between NDVI anomaly and temperature anomaly, and between NDVI anomaly and precipitation anomaly for the summer months of June, July, August and September over the period 2000 to 2010. The precipitation and temperature anomalies are based on the 32-day periods described earlier, and summer correlation values are highest when considering the month immediately prior to the NDVI observation compared with other time lags. Figure $2 a$ and $b$ show the results (where significant at $95 \%$ ) for the 1 month lag and indicate that, for much of Europe, summer (JJAS) NDVI is positively correlated with precipitation and negatively correlated with temperature.

We confirm higher absolute correlations between summer precipitation and summer NDVI than absolute correlations between summer temperature and NDVI by inspecting histograms of probability density, and quantile-quantile $(Q-Q)$ plots of the squares of the correlation coefficients. The differences are small, but statistically significant (Fig. 3). The positive correlations of NDVI with precipitation and negative correlations with temperature confirm the findings by Lobo and Maisongrande (2006), based on data from 1999 to 2003, that much of the geographic structure in NDVI anomaly for 2003 is governed by atmospheric water stress as measured by the difference between precipitation and potential evapotranspiration.

The results of our analysis for the extended period of 2000-2010 of temporal anomalies and analysis of precipitation versus vegetation correlations and vegetation versus temperature correlations are similar to those of previous studies. In the following it is explored how vegetation stress, expressed as an increased DTR or decreased NDVI, depends on vegetation height.

Vegetation height estimates based on GLAS data are retrieved at intervals along the ICESat tracks as shown in Fig. 5; typical sampling rates within a $50 \mathrm{~km} \times 50 \mathrm{~km}$ square 


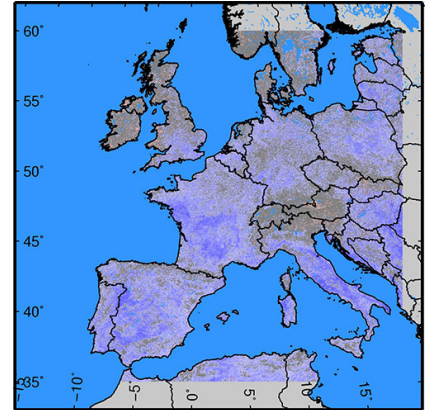

(a)

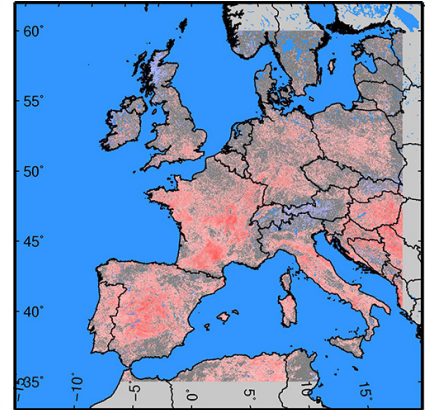

(b)
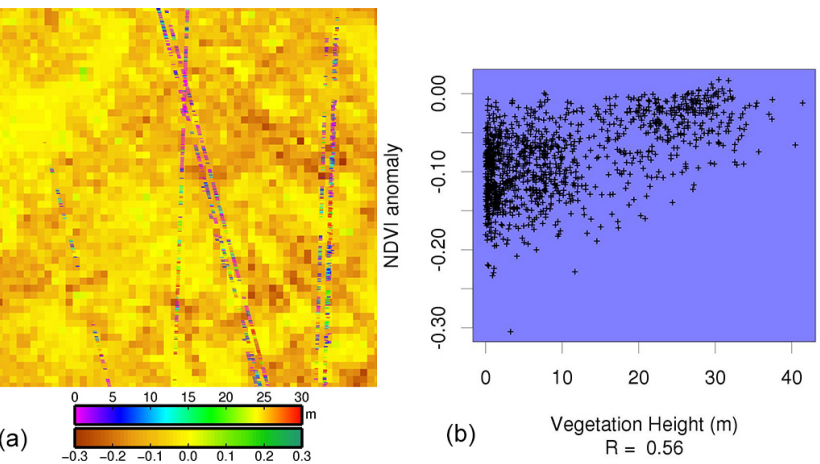

Figure 4. (a) An example of the distribution of vegetation height data points within a $50 \mathrm{~km}$ square. The square corresponds to the one indicated in Fig. 6 and the underlying image is the NDVI anomaly for 29 August 2003. (b) Scatter plot of the data in (a). The correlation coefficient (Pearson's $R$ ) for this square is 0.56 .

of browning, and inferred reduction in GPP, than taller vegetation.

The magnitude of the correlation between vegetation height and NDVI anomaly over Europe, for the period under consideration, increases with precipitation deficit and with temperature anomaly. Figure 7 shows the correlation as a function of precipitation deficit under regions experiencing temperature anomalies of $+1{ }^{\circ} \mathrm{C},+2{ }^{\circ} \mathrm{C}$ and $+3{ }^{\circ} \mathrm{C}$.

As an alternative test of the relationship between vegetation height and response to drought we make use of the Corine Land Cover classes. For each vegetation height point we also extract the CLC2000 class and separate the associated NDVI anomalies into two groups according to CLC2000 class. Group 1 includes land cover classes 10 to 22 which are sub-classes of "Artificial, non-agricultural vegetated areas", "Arable land", "Permanent crops", "Pastures", "Heterogeneous agricultural areas", and 26 to 29 , "Scrub and/or herbaceous vegetation associations", Group 2 includes classes 23 to 25 , "Forests". Within each $50 \mathrm{~km}$ square we use a $t$ test to decide whether the mean NDVI anomaly is significantly lower (i.e. more negative) for Group 1 than for Group 2. The differences in mean NDVI anomaly between Group 1 and Group 2 are shown in Fig. 8. A comparison of Figs. 6 and 8 shows that the distributions and relative strengths of the relationships between NDVI anomaly and either vegetation height or vegetation class are very similar.

Our working hypothesis is that tall vegetation has deeper roots and therefore has access to a larger amount of soil moisture at greater depths. The greater availability of water would lead to a larger heat capacity of the canopy and a smaller DTR (Collatz et al., 2000). The DTR, obtained from MODIS data, is correlated with vegetation height similar to the approach adopted for the NDVI. In August 2003 we find a negative correlation between vegetation height and DTR (Fig. 9) over much of central and western Europe. Over Germany, $95 \%$ of correlations significant at the $95 \%$ level are 


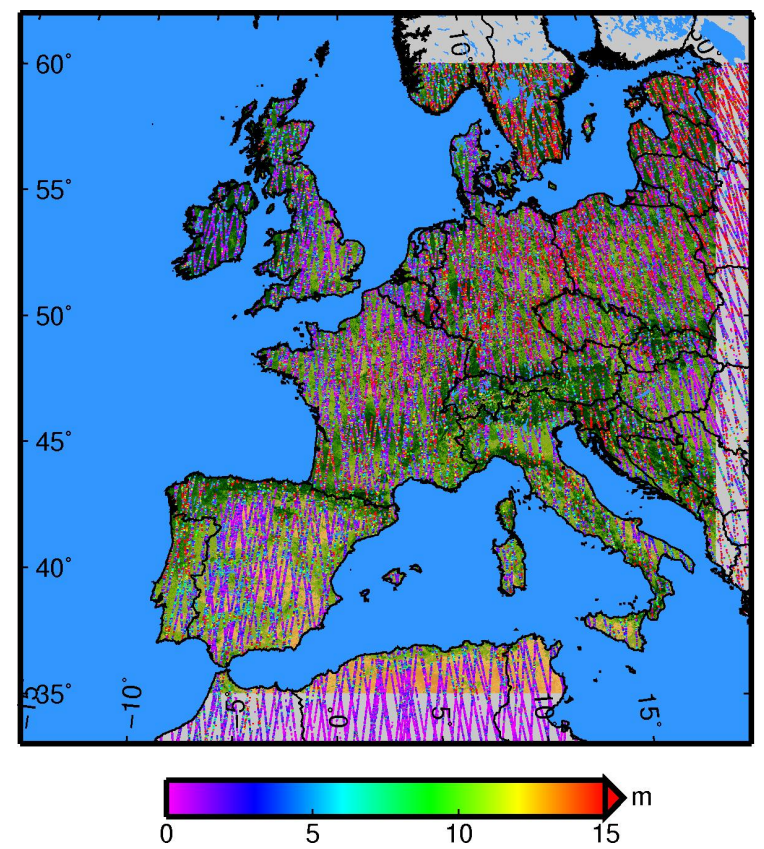

Figure 5. ICESat GLAS derived vegetation heights. The underlying image is NDVI for 29 August 2003. Each point represents a height retrieval from data collected between 2003 and 2009, with an alongtrack sampling rate of about $172 \mathrm{~m}$. Heights greater than $15 \mathrm{~m}$ are in red.

negative, with $78 \%$ less than -0.2 . Over France, $88 \%$ are negative with $51 \%$ less than -0.2 . Thus during the $2003 \mathrm{Eu}-$ ropean drought taller vegetation is associated with a smaller anomaly in leaf area index, a smaller DTR and likely a larger canopy heat capacity and moisture availability. Other (nondrought) years did not show a variation in DTR or NDVI anomaly with canopy height (Appendix A).

It is not possible to confirm the proposed relationship between rooting depth and vegetation height using the ISLSCP data set (Figs. 10a-c). Both the $1^{\circ} \times 1^{\circ}$ extrapolated rootingdepth data (Schenk and Jackson, 2009) and climatological soil water availability estimates (Kleidon and Heimann, 1998; Kleidon, 2011) show a negative relationship with vegetation height. Rooting-depth observations from the global database of root profiles show a weak negative relationship with vegetation height (Fig. 10c); the regression line is not significant. The density of the root measurements is insufficient to analyse the relationship with vegetation index and DTR over short distances similar to our analysis of vegetation height.

\section{Discussion}

In order to understand the impact of mid-latitude land-cover changes under future climate warming and drought, landatmosphere feedbacks involving albedo, soil moisture and the vegetation canopy must be considered.

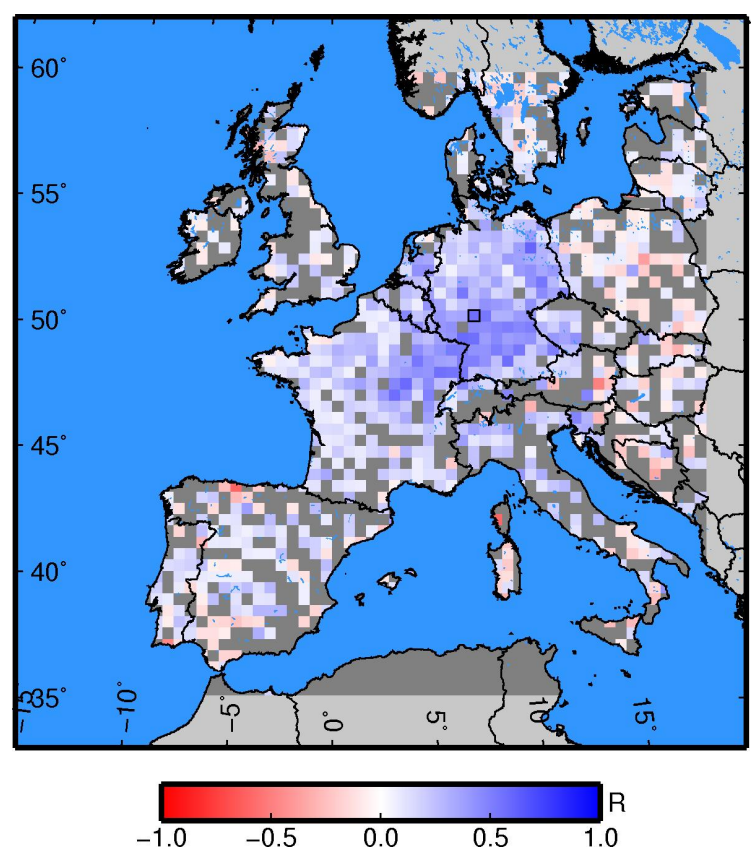

Figure 6. Correlation coefficient (Pearson's $R$, where significant at $95 \%$ ) between vegetation height and NDVI anomaly for 29 August 2003, within $50 \mathrm{~km}$ squares. The square outlined in black in Germany corresponds to that used in Fig. $4 \mathrm{a}$ and $\mathrm{b}$.

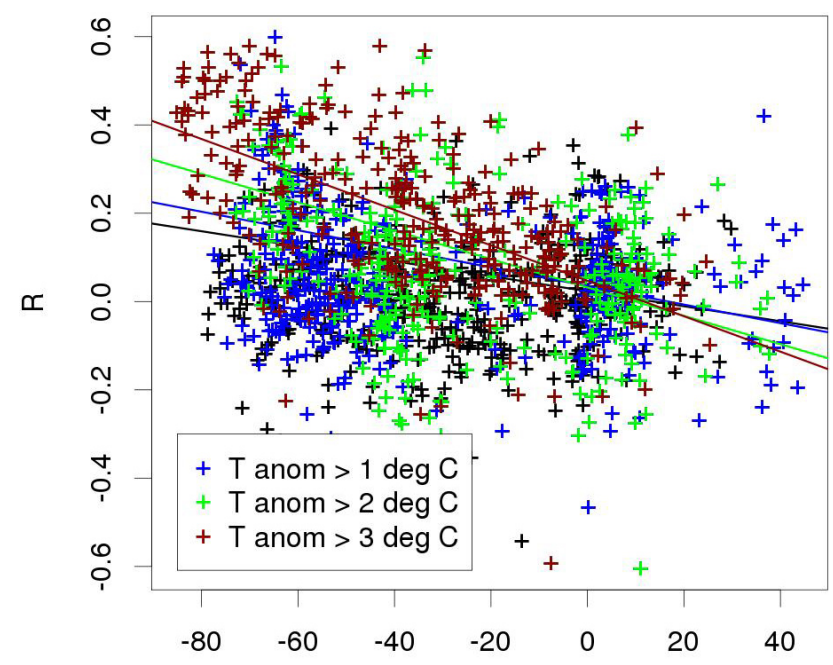

32-day Precipitation anomaly (mm)

Figure 7. The correlations between vegetation height and NDVI anomaly $(R)$ as mapped in Fig. 6 against the precipitation anomaly over the preceding 32-day period. Coloured data points represent $R$ values under varying magnitudes of temperature anomaly.

Our results (Fig. 6) show that for much of Europe tall vegetation experienced less browning under the 2003 drought indicating a greater degree of tolerance to extended drought stress than short vegetation. The greater the temperature anomaly the more marked was the height-conferred tolerance 


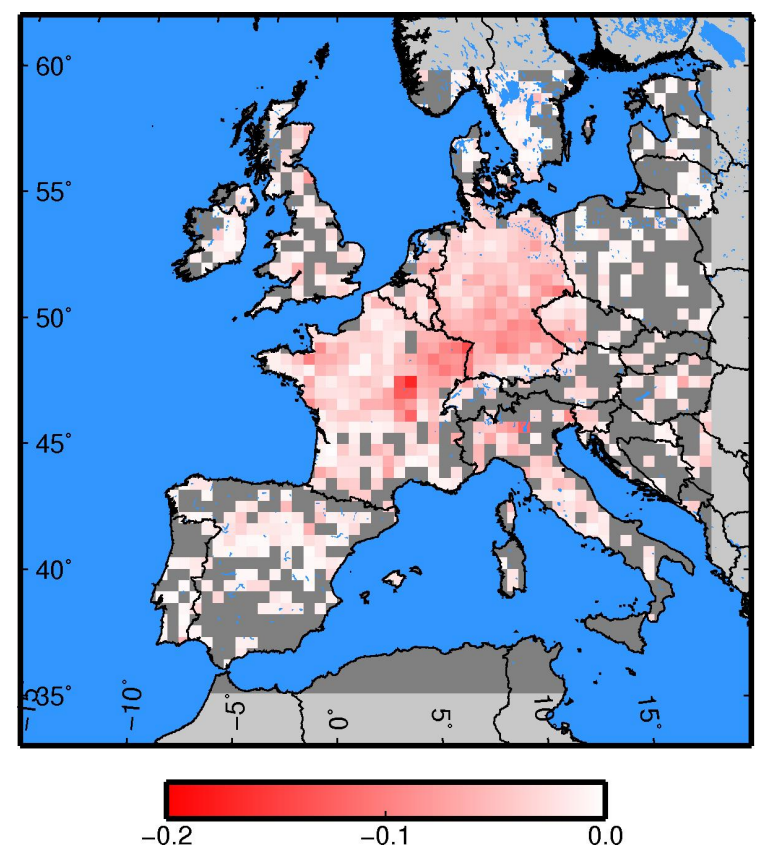

Figure 8. Mean NDVI anomalies for data points in Corine Land Cover (CLC) group 1 minus mean NDVI anomalies for data points in CLC group 2, where the mean difference is significant at the $95 \%$ level. See text and Table 1 for a description of groups 1 and 2 .

for drought effects (Fig. 7). The same variation in drought tolerance is shown between different vegetation classes, with forest classes showing a greater tolerance than the group of classes including crops and pastures. This tolerance of tall vegetation to drought suggests that, for Europe, an increase in forest cover will help to mitigate the effect of predicted climate change on biomass production.

The negative correlation between vegetation height and DTR is an effect that does not persist under non-drought conditions. An inspection of the geographic distribution of the correlation for 2002, 2003 and 2004 shows interannual variability in the effect which closely corresponds to MODIS LST and also generally to GPCP precipitation anomaly patterns (Appendix Figs. A1-A3), particularly over northwestern Europe. Further east, over Poland, the weaker correlation even in 2003, may be a function of the dominance in this region of taller vegetation (Fig. 10d) masking any statistically significant signal. Over Spain the signal appears more persistent, possibly owing to generally drier soil conditions.

Zaitchik et al. (2006) and Teuling and Seneviratne (2008) found total short-wave albedo effects for Europe to be minimal under water-stress conditions owing to compensating physiological effects at visible and near-infrared wavelengths for all vegetation types. Additionally, the apparent ability of tall vegetation to dampen the DTR under drought and heatwave conditions in comparison with short vegetation (Fig. 9) suggests that, in Europe, increasing forest cover will have a moderating effect on local climate which is more significant

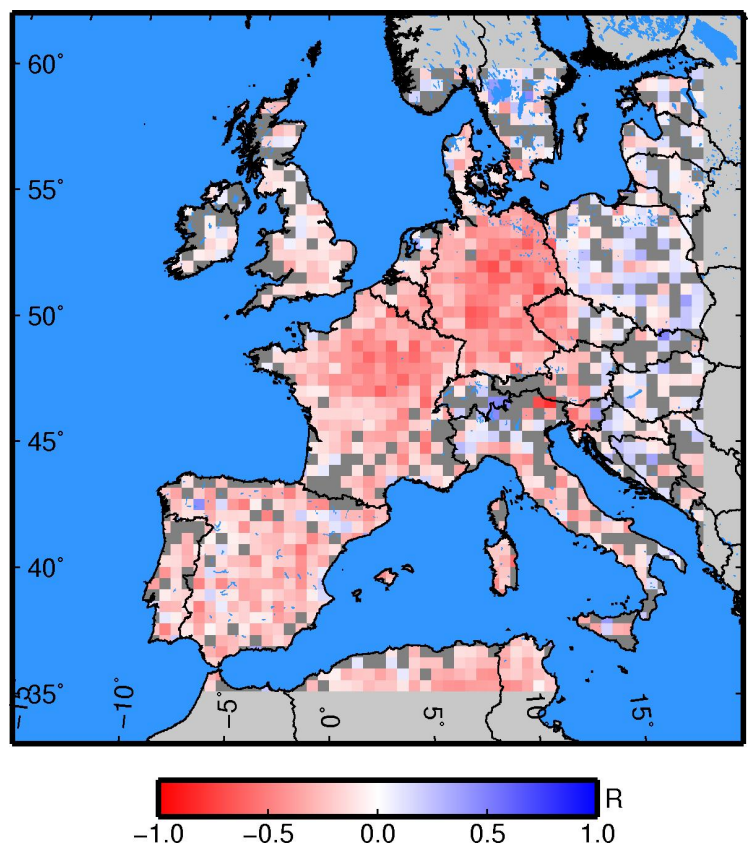

Figure 9. Correlation coefficient (Pearson's $R$, where significant at $95 \%$ ) between vegetation height and diurnal temperature range for day 5 August 2003, within $50 \mathrm{~km}$ squares.

than any albedo changes. Thus vegetation height or parameters linked to vegetation height are dominant in explaining the tolerance of vegetation to drought.

The mechanisms whereby tall vegetation is both able to resist drought and modify heatwave DTRs may include access to deeper soil water or more effective water conservation through reduced evapotranspiration, for example by canopy shading of the soil or by increasing canopy resistance to water vapour flux into the atmosphere. Stomatal closure at the beginning of the drought could help to conserve water which would lead to a larger supply of water at later stages of the drought. It is unlikely to be a factor during later stages of the drought since it would lead to a reduction in latent heat and an increase in DTR, unless loss of water to the canopy air space by stomatal closure is compensated by the higher aerodynamic resistance of the canopy.

The ISLSCP rooting-depth data (Schenk and Jackson, 2009) showed a negative correlation of vegetation height with both rooting depth and soil water availability to plants (Fig. 10a and b). The individual global rooting-depth observations did not allow any conclusions to be drawn on the relationship between vegetation height and rooting depth (Fig. 10c). There are potential limitations to the rootingdepth data sets. Observations of rooting depth are usually limited to the first $3 \mathrm{~m}$ of soil (Schenk and Jackson, 2009) and do not include estimates of the maximum rooting depth or of the length of taproots which are essential for vegetation to access water at even greater depths. Other studies determining maximum rooting depth for different vegetation 
a) Schenk \& Jackson global rooting depth

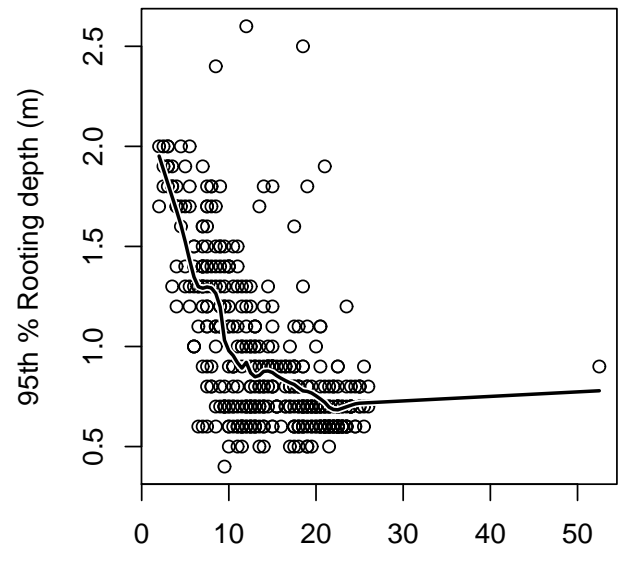

90th \% Vegetation height $(\mathrm{m})$

c) Schenk and Jackson observed

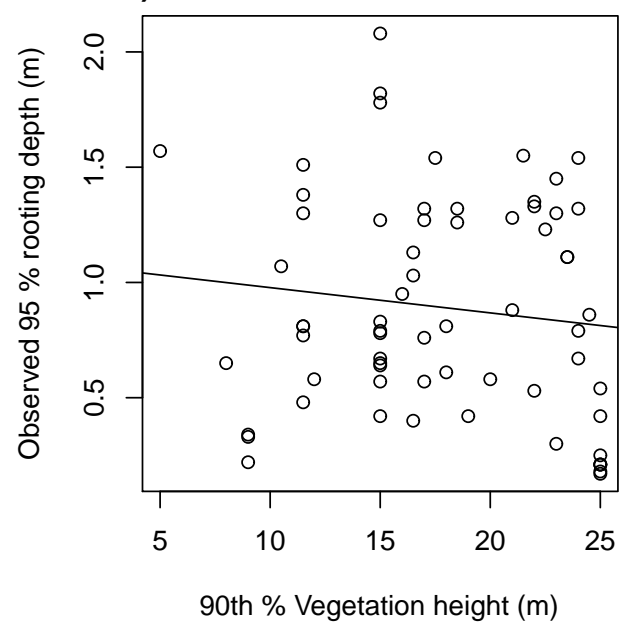

b) Kleidon

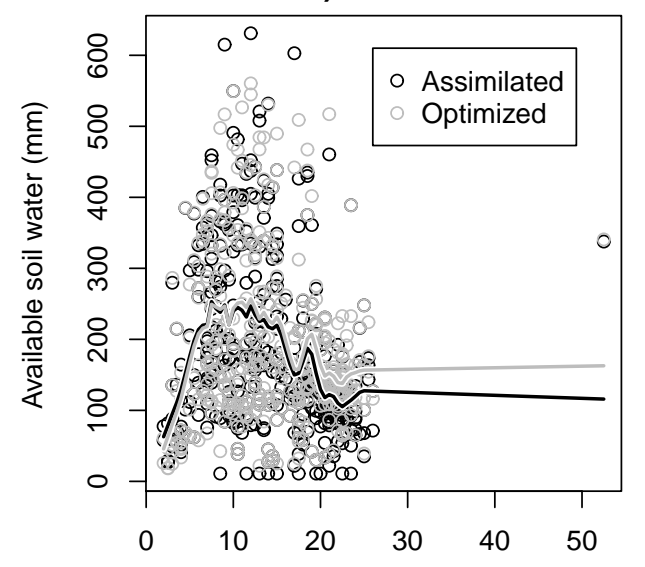

90th \% Vegetation height $(\mathrm{m})$
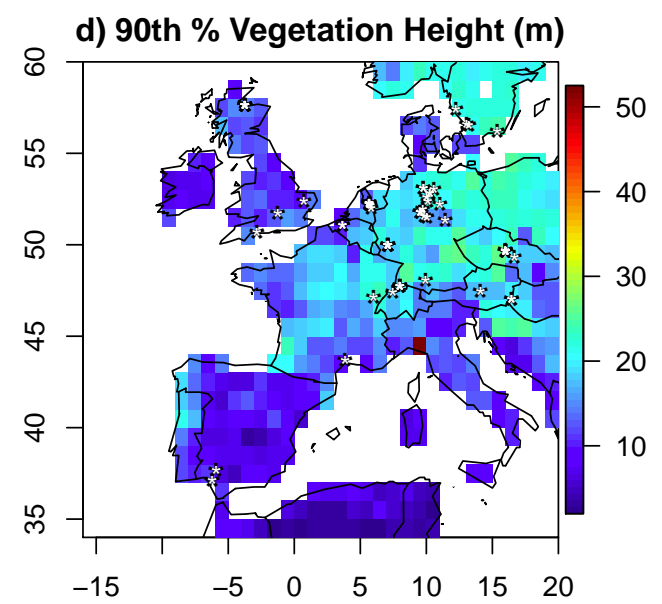

Figure 10. (a) ISLSCP 90th percentile rooting depths from the global gridded product (Schenk and Jackson, 2009) against collocated 90th percentile gridded GLAS vegetation heights. (b) ISLSCP modelled soil water availability (Kleidon, 2011) against 90th percentile gridded GLAS vegetation heights. Dark circles represent the assimilation product and light circles the optimization product. (c) The 95th percentiles of individual root-depth observations against collocated 90th percentile gridded GLAS vegetation heights. (d) 90th percentile gridded GLAS vegetation heights used in the scatter plots; the stars mark the locations of the root profile observations.

type (Canadell et al., 1996; Schenk and Jackson, 2002a) support our hypothesis that taller vegetation is linked with larger rooting depth. Another potential limitation to the global rooting depth data is that interpolation of rooting depth on landcover classifications in some cases have problems in distinguishing between broad-leaf trees and crops (Scepan, 1999). We find a negative correlation between vegetation height and soil water availability (Fig. 10c). The soil water availability is derived for mean climatological conditions (Kleidon and Heimann, 1998; Kleidon, 2011) and for these conditions taller vegetation has access to a continuous supply of water and so less storage of soil water is needed to maximize productivity.

A tall, closed canopy with a large amount of leaf biomass reduces evaporation by shading of the soil and increases the resistance to transport of water vapour from the canopy air space into the overlying atmosphere. The second process increases the humidity of the canopy air space and thereby increases its heat capacity. Our study does not allow the quantification of the effects of roots and greater access to deep soil water on the one hand and the effects of a tall closed canopy and associated greater heat capacity on the other, although these two factors are likely to occur simultaneously. However, the DTR is most sensitive to temperature variations in the top leaves of the canopy where the effects of evaporation and water availability play an important role. This would suggest that greater water availability to tall vegetation is an important factor in explaining its greater drought tolerance. 


\section{Conclusions}

The 2003 drought provides an opportunity to explore differences in the response of short and tall vegetation to an extended period of water stress. For tall vegetation we find less negative anomalies in NDVI and lower values for the DTR than for short vegetation. The associations shown here point towards the importance of soil water availability or a closed canopy. Both effects increase the availability of water vapour in the canopy air space and can explain the relatively modest reductions in NDVI and smaller DTR.

Based on the results of our present analysis we would expect warmer conditions for the summer for a land-cover change simulation where tall vegetation is converted to short vegetation with an important caveat that the comparison of land-surface models by Pitman et al. (2009) did not pertain to a drought. A simulation of the 2003 drought with the investigated models would likely reveal whether the response of tall versus short vegetation is correctly represented within the models. It is also likely that for Europe, land-cover changes resulting in more short vegetation would amplify future summer heatwaves and droughts compared with increasing areas of tall vegetation.
Our results suggest that land-surface models would benefit from the inclusion of maximum rooting depth as a parameter but that existing global data sets, which include root depths only down to $3 \mathrm{~m}$, may be inadequate. We find that over Europe the geographic distribution of root depths within these global data sets does not accurately reflect the relationship between vegetation height and root depth. 
Appendix A: DTR-vegetation-height correlations, and climate anomalies

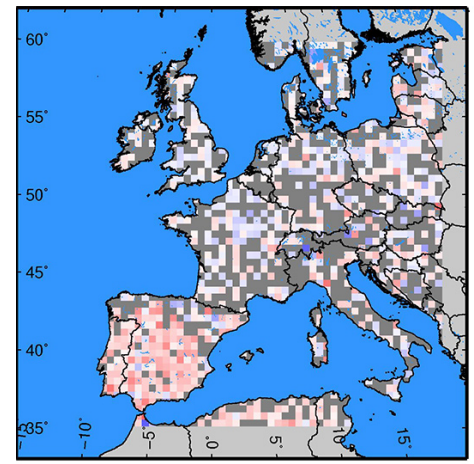

(a)

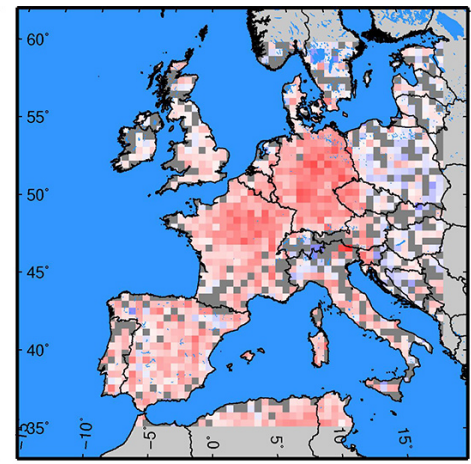

(b)

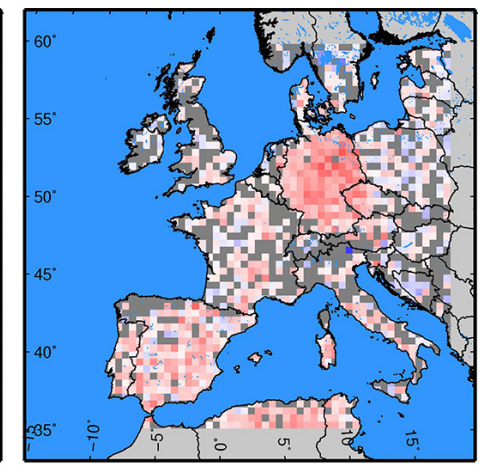

(c)

Figure A1. Correlation coefficient (Pearson's $R$, where significant at $95 \%$ ) between vegetation height and diurnal temperature range for 5 August (a) 2002, (b) 2003, (c) 2004. Dark grey indicates areas not investigated or areas where $R$ is not significant.

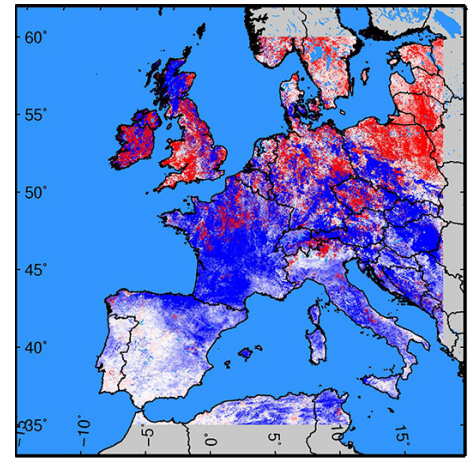

(a)

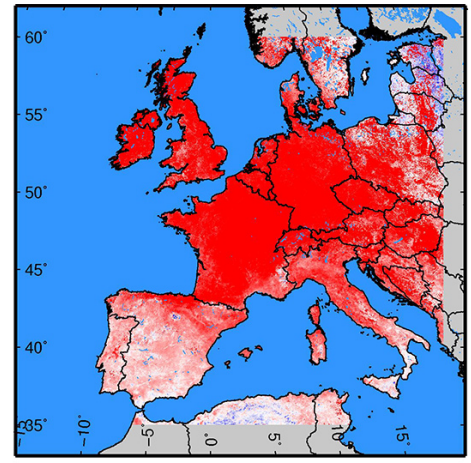

(b)

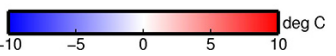

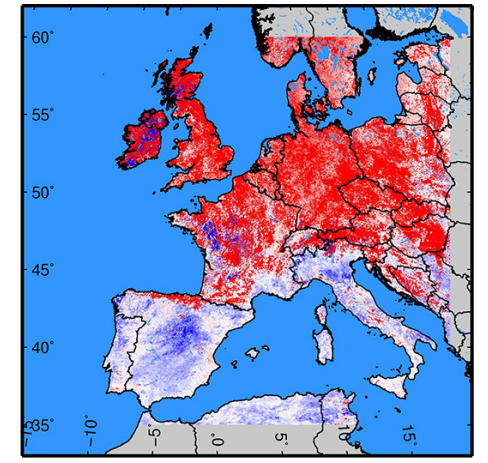

(c)

Figure A2. MODIS Aqua daytime land surface temperature anomalies relative to the 2002-2012 mean for 5 August (a) 2002, (b) 2003, (c) 2004.

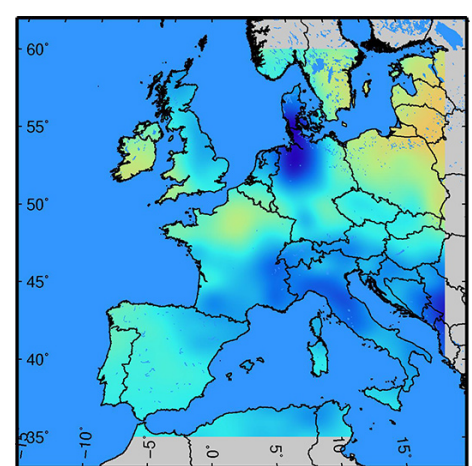

(a)

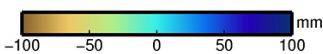

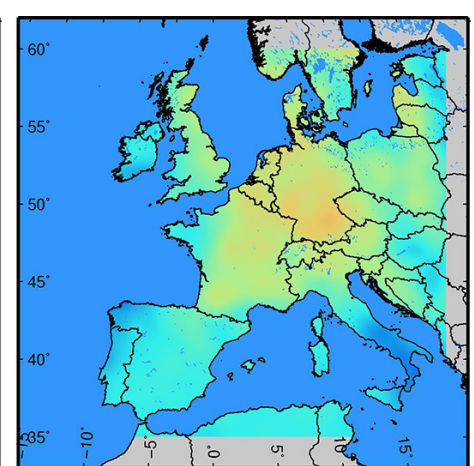

(b)

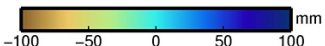

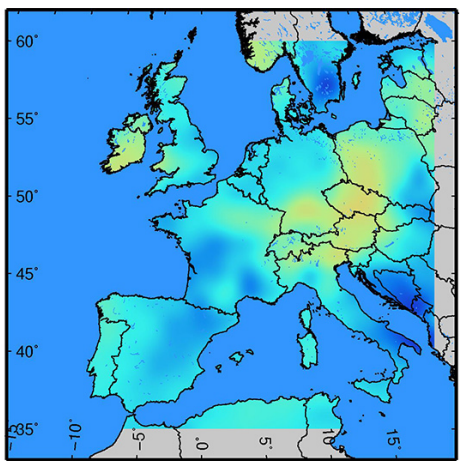

(c)

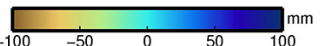

Figure A3. Global Precipitation Climatology Project (GPCP) precipitation anomalies relative to the 2000-2010 mean, accumulated for the 32-day period prior to 5 August (a) 2002, (b) 2003, (c) 2004. 
Acknowledgements. The MODIS NDVI and land-surface temperature data were obtained through the online Data Pool at the NASA Land Processes Distributed Active Archive Center (LP DAAC), USGS/Earth Resources Observation and Science (EROS) Center, Sioux Falls, South Dakota (https://lpdaac.usgs.gov/get_data). The gridded GPCP precipitation data were obtained from http://precip.gsfc.nasa.gov. The 1DD data were provided by the NASA/Goddard Space Flight Center's Mesoscale Atmospheric Processes Laboratory, which develops and computes the 1DD as a contribution to the GEWEX Global Precipitation Climatology Project. ERA-Interim data were downloaded from the European Centre for Medium-Range Weather Forecasts data server. S. L. Bevan was funded by the NERC National Centre for Earth Observation. Computational support was provided by the Climate Change Consortium of Wales (C3W). We thank Axel Kleidon and three reviewers for their comments.

Edited by: M. Reichstein

\section{References}

Berrisford, P., Dee, D., Poli, P., Brugge, R., Fielding, K., Fuentes, M., Kallberg, P., Kobayashi, S., Uppala, S., and Simmons, A.: The ERA-Interim archive Version 2.0, ERA Report Series 1, ECMWF, Shinfield Park, Reading, UK, 2011.

Betts, A. K., Ball, J. H., and McCaughey, J. H.: Near-surface climate in the boreal forest, J. Geophys. Res., 106, 33529-33541, doi:10.1029/2001JD900047, 2001a.

Betts, A. K., Viterbo, P., Beljaars, A. C. M., and van den Hurk, B. J. J. M.: Impact of BOREAS on the ECMWF forecast model, J. Geophys. Res., 106, 33593-33604, doi:10.1029/2001JD900056, 2001b.

Bonan, G. B.: Forest and climate change: forcings, feedbacks and the climate benefits of forests, Science, 320, 1444-1449, doi:10.1126/science.1155121, 2008.

Bonan, G. B., Pollard, D., and Thompson, S. L.: Effects of boreal forest vegetation on global climate, Nature, 359, 716-718, doi:10.1038/359716a0, 1992.

Canadell, J., Jackson, R. B., Ehleringer, J. B., Mooney, H. A., Sala, O. E., and Schulze, E. D.: Maximum rooting depth of vegetation types at the global scale, 108, 583-595, doi:10.1007/bf00329030, 1996.

Charney, J., Quirk, W. J., Chow, S. H., and Kornfield, J.: Comparative study of effects of albedo change on drought in semi-arid regions, J. Atmos. Sci., 34, 1366-1385, 1977.

Ciais, P., Reichstein, M., Viovy, N., Granier, A., Ogee, J., Allard, V., Aubinet, M., Buchmann, N., Bernhofer, C., Carrara, A., Chevallier, F., De Noblet, N., Friend, A. D., Friedlingstein, P., Grunwald, T., Heinesch, B., Keronen, P., Knohl, A., Krinner, G., Loustau, D., Manca, G., Matteucci, G., Miglietta, F., Ourcival, J. M., Papale, D., Pilegaard, K., Rambal, S., Seufert, G., Soussana, J. F., Sanz, M. J., Schulze, E. D., Vesala, T., and Valentini, R.: Europe-wide reduction in primary productivity caused by the heat and drought in 2003, Nature, 437, 529-533, doi:10.1038/nature03972, 2005.

Collatz, G. J., Bounoua, L., Los, S. O., Randall, D. A., Fung, I. Y., and Sellers, P. J.: A mechanism for the influence of vegetation on the response of the diurnal temperature range to changing climate, Geophys. Res. Lett., 27, 3381-3384, doi:10.1029/1999GL010947, 2000.

Coret, L., Maisongrande, P., Boone, A., Lobo, A., Dedieu, G., and Gouaux, P.: Assessing the impacts of the 2003 hot and dry spell with SPOT HRVIR images time series over southwestern France, Int. J. Remote Sens., 26, 2461-2469, doi:10.1080/01431160500057236, 2005.

Costa, M. H. and Foley, J. A.: Combined effects of deforestation and doubled atmospheric $\mathrm{CO}_{2}$ concentrations on the climate of Amazonia, J. Climate, 13, 18-34, doi:10.1175/15200442(2000)013<0018:CEODAD>2.0.CO;2, 2000.

Dirmeyer, P. A.: Vegetation stress as a feedback mechanism in midlatitude drought, J. Climate, 7, 1463-1483, doi:10.1175/15200442(1994)007<1463:VSAAFM>2.0.CO;2, 1994.

EEA, EEA data service: Corine land cover 2000 vector by country (CLC2000), available at: http://www.eea.europa.eu/ data-and-maps/data/corine-land-cover-2000-raster-2, last access: 16 October 2013.

Fischer, E. M., Seneviratne, S. I., Vidale, P. L., Luthi, D., and Schar, C.: Soil moisture - atmosphere interactions during the 2003 European summer heat wave, J. Climate, 20, 5082-5099, doi:10.1175/JCLI4288.1, 2007.

García-Herrera, R., Díaz, J., Trigo, R. M., Luterbacher, J., and Fischer, E. M.: A review of the European summer heat wave of 2003, Cr. Rev. Environ. Sci. Technol., 40, 267-306, doi:10.1080/10643380802238137, 2010.

Gobron, N., Pinty, B., Mélin, F., Taberner, M., Verstraete, M. M., Belward, A., Lavergne, T., and Widlowski, J.: The state of vegetation in Europe following the 2003 drought, Int. J. Remote Sens., 26, 2013-2020, doi:10.1080/01431160412331330293, 2005.

Hall, F. G., Brown de Colstoun, E., Collatz, G. J., Landis, D., Dirmeyer, P., Betts, A., Huffman, G. J., Bounoua, L., and Meeson, B.: ISLSCP Initiative II global data sets: Surface boundary conditions and atmospheric forcings for land-atmosphere studies, J. Geophys. Res., 111, D22S01, doi:10.1029/2006jd007366, 2006.

Huffman, G. J., Adler, R. F., Morrissey, M. M., Bolvin, D. T., Curtis, S., Joyce, R., McGavock, B., and Susskind, J.: Global precipitation at one-degree daily resolution from multisatellite observations, J. Hydrometeorol., 2, 36-50, doi:10.1175/15257541(2001)002<0036:GPAODD>2.0.CO;2, 2001.

Huffman, G. J., Adler, R. F., Bolvin, D. T., and Gu, G.: Improving the global precipitation record: GPCP Version 2.1, Geophys. Res. Lett., 36, L17808, doi:10.1029/2009GL040000, 2009.

Huffman, G. J., Bolvin, D. T., and Adler, R. F.: GPCP Version 2.2 Combined Precipitation Data Set, available at: http://www.ncdc. noaa.gov/oa/wmo/wdcamet-ncdc.html, 2011.

Jolly, W. M., Dobbertin, M., Zimmerman, N. E., and Reichstein, M.: Divergent vegetation growth responses to the 2003 heat wave in the Swiss Alps, Geophys. Res. Lett., 32, L18409, doi:10.1029/2005GL023252, 2005.

Klein Goldewijk, K. and Ramankutty, N.: Land cover change over the last three centuries due to human activities: the availability of new global data sets, GeoJournal, 61, 335-344, 2004.

Kleidon, A.: ISLSCP Initiative II Collection, edited by: Hall, F. G., Collatz, G., Meeson, B., Los, S., Brown de Colstoun, E., and Landis, D., Data set, available at: http://daac.ornl.gov/ from Oak Ridge National Laboratory Distributed Active Archive Center, 
Oak Ridge, Tennessee, USA, doi:10.3334/ORNLDAAC/1006, 2011.

Kleidon, A. and Heimann, M.: A method of determining rooting depth from a terrestrial biosphere model and its impacts on the global water and carbon cycle, Glob. Change Biol., 4, 275-286, doi:10.1046/j.1365-2486.1998.00152.x, 1998.

Knorr, W.: Satellitengestuetzte Fernerkundung und Modellierung des globalen $\mathrm{CO}_{2}^{-}$Austauschs der Landvegetation: Versuch einer Synthese, Ph.D. Thesis, University of Hamburg, Germany, 193 pp., available in English at: http://www.mpimet.mpg.de/gbc/ wolfgang/index.html, ISSN 0938-5177, 1997.

Lobo, A. and Maisongrande, P.: Stratified analysis of satellite imagery of SW Europe during summer 2003: the differential response of vegetation classes to increased water deficit, Hydrol. Earth Syst. Sci., 10, 151-164, doi:10.5194/hess-10-151-2006, 2006.

Loew, A., Holmes, T., and de Jeu, R.: The European heat wave 2003: early indicators from multisensoral microwave remote sensing, J. Geophys. Res., 114, D05103, doi:10.1029/2008JD010533, 2009.

Los, S. O., Weedon, G. P., North, P. R. J., Kaduk, J. D., Taylor, C. M., and Cox, P. M.: An observation-based estimate of the strength of rainfall-vegetation interactions in the Sahel, Geophys. Res. Lett., 33, L16402, doi:10.1029/2006GL027065, 2006.

Los, S. O., Rosette, J. A. B., Kljun, N., North, P. R. J., Chasmer, L., Suárez, J. C., Hopkinson, C., Hill, R. A., van Gorsel, E., Mahoney, C., and Berni, J. A. J.: Vegetation height and cover fraction between $60^{\circ} \mathrm{S}$ and $60^{\circ} \mathrm{N}$ from ICESat GLAS data, Geosci. Model Dev., 5, 413-432, doi:10.5194/gmd-5-413-2012, 2012.

Luterbacher, J., Dietrich, D., Xoplaki, E., Grosjean, M., and Wanner, H.: European seasonal and annual temperature variability, trends, and extremes since 1500, Science, 303, 1499-1503, doi:10.1126/science.1093877, 2004

Myneni, R. B. and Williams, D. L.: On the relationship between FAPAR and NDVI, Remote Sens. Environ., 49, 200-211, 1994.

Pitman, A. J., de Noblet-Ducoudre, N., Cruz, F. T., Davin, E. L., Bonan, G. B., Brovkin, V., Claussen, M., Delire, C., Ganzeveld, L., Gayler, V., van den Hurk, B. J. J. M., Lawrence, P. J., van der Molen, M. K., Mueller, C., Reick, C. H., Seneviratne, S. I., Strengers, B. J., and Voldoire, A.: Uncertainties in climate responses to past land cover change: first results from the LUCID intercomparison study, Geophys. Res. Lett., 36, L14814, doi:10.1029/2009GL039076, 2009.

Reichstein, M., Ciais, P., Papale, D., Valentini, R., Running, S., Viovy, N., Cramer, W., Granier, A., Ogée, J., Allard, V., Aubinet, M., Bernhofer, C., Buchmann, N., Carrara, A., Grünwald, T., Heimann, M., Heinesch, B., Knohl, A., Kutsch, W., Loustau, D., Manca, G., Matteucci, G., Miglietta, F., Ourcival, J. M., Pilegaard, K., Pumpanen, J., Rambal, S., Schaphoff, S., Seufert, G., Soussana, J. F., Sanz, M. J., Vesala, T., and Zhao, M.: Reduction of ecosystem productivity and respiration during the European summer 2003 climate anomaly: a joint flux tower, remote sensing and modelling analysis, Glob. Change Biol., 13, 634-651, doi:10.1111/j.1365-2486.2006.01224.x, 2007.

Rosette, J. A. B., North, P. R. J., and Suarez, J. C.: Vegetation height estimates for a mixed temperate forest using satellite laser altimetry, Int. J. Remote Sens., 29, 1475-1493, doi:10.1080/01431160701736380, 2008.
Sagan, C., Toon, O. B., and Pollack, J. B.: Anthropogenic albedo changes and the Earth's climate, Science, 206, 1363-1368, 1979.

Samanta, A., Ganguly, S., Hashimoto, H., Devadiga, S., Vermote, E., Knyazikhin, Y., Nemani, R. R., and Myneni, R. B.: Amazon forests did not green up during the 2005 drought, Geophys. Res. Lett., 37, L05401, doi:10.1029/2009GL042154, 2010.

Scepan, J.: Thematic validation of high-resolution global land-cover data sets, Photogrammetric engineering and remote sensing, 65, 1051-1060, 1999.

Schär, C., Vidale, P. L., Luthi, D., Frei, C., Haberli, C., Liniger, M. A., and Appenzeller, C.: The role of increasing temperature variability in European summer heatwaves, Nature, 427, 332-336, doi:10.1038/nature02300, 2004.

Schenk, H. J. and Jackson, R. B.: Rooting depths, lateral root spreads and below-ground/above-ground allometries of plants in water-limited ecosystems, J. Ecol., 90, 480-494, doi:10.1046/j.1365-2745.2002.00682.x, 2002a.

Schenk, H. J. and Jackson, R. B.: The global biogeography of roots, Ecol. Monogr., 72, 311-328, doi:10.2307/3100092, 2002b.

Schenk, H. J. and Jackson, R. B.: Global Distribution of Root Profiles in Terrestrial Ecosystems. Data set, available at: http: //daac.ornl.gov/ from Oak Ridge National Laboratory Distributed Active Archive Center, Oak Ridge, Tennessee, USA, doi:10.3334/ORNLDAAC/660, 2003.

Schenk, H. J. and Jackson, R. B.: ISLSCP Initiative II Collection, edited by: Hall, F. G., Collatz, G., Meeson, B., Los, S., Brown de Colstoun, E., and Landis, D., Data set, available at http://daac.ornl.gov/ from Oak Ridge National Laboratory Distributed Active Archive Center, Oak Ridge, Tennessee, USA, doi:10.3334/ORNLDAAC/929, 2009.

Sellers, P. J.: Canopy reflectance, photosynthesis and transpiration, Int. J. Remote Sens., 6, 1335-1372, 1985.

Teuling, A. J. and Seneviratne, S. I.: Contrasting spectral changes limit albedo impact on land-atmosphere coupling during the 2003 European heat wave, Geophys. Res. Lett., 35, L03401, doi:10.1029/2007g1032778, 2008.

Teuling, A. J., Seneviratne, S. I., Stockli, R., Reichstein, M., Moors, E., Ciais, P., Luyssaert, S., van den Hurk, B., Ammann, C., Bernhofer, C., Dellwik, E., Gianelle, D., Gielen, B., Grunwald, T., Klumpp, K., Montagnani, L., Moureaux, C., Sottocornola, M., and Wohlfahrt, G.: Contrasting response of European forest and grassland energy exchange to heatwaves, Nat. Geosci., 3, 722-727, doi:10.1038/ngeo950, 2010.

Thomas, G. and Rowntree, P. R.: The boreal forests and climate, Q. J. Roy. Meteor. Soc., 118, 469-497, doi:10.1002/qj.49711850505, 1992.

van den Hurk, B. J. J. M., Viterbo, P., and Los, S. O.: Impact of leaf area index seasonality on the annual land surface evaporation in a global circulation model, J. Geophys. Res.-Atmos., 108, 41914199, 2003.

Xue, Y., De Sales, F., Vasic, R., Mechoso, C. R., Arakawa, A., and Prince, S.: Global and seasonal assessment of interactions between climate and vegetation biophysical processes: a GCM study with different land-vegetation representations, J. Climate, 23, 1411-1433, doi:10.1175/2009JCLI3054.1, 2010.

Zaitchik, B. F., Macaldy, A. K., Bonneau, L. R., and Smith, R. B.: Europe's 2003 heat wave: a satellite view of impacts and land-atmosphere feedbacks, Int. J. Climatol., 26, 743-769, doi:10.1002/joc.1280, 2006. 